\title{
The use of a formula-based ketogenic diet in children with refractory epilepsy
}

\author{
O uso da dieta cetogênica a base de fórmula em crianças com epilepsia refratária \\ Letícia Pereira de Brito Sampaio', Cristina Takakura², Maria Luiza Giraldes de Manreza
}

\begin{abstract}
The ketogenic diet (KD) is a nonpharmacologic treatment that has been used for refractory epilepsy since 1921. The KD is a high-fat, low-carbohydrate, and restricted protein diet, which is calculated and weighed for each individual patient. Introducing and maintaining the diet for a long time remains a challenge. In this study, we evaluated the acceptability, tolerance, and efficacy of a formula-based KD in 10 children with refractory epilepsy. The ketogenic formula tested herein caused only mild KD-related adverse events and adequate adherence. Moreover, $60 \%$ of patients had more than $50 \%$ seizure frequency reduction and $10 \%$ were seizure-free.
\end{abstract}

Keywords: ketogenic diet; epilepsy; diet therapy

\section{RESUMO}

A dieta cetogênica (DC) é um tratamento não farmacológico utilizado para epilepsia refratária desde 1921. A DC possui um alto teor de gordura, sendo restrita em carboidratos e adequada em proteínas, calculada e pesada para cada paciente. A introdução e manutenção da DC por um tempo prolongado permanece um desafio. Neste estudo foi avaliada a aceitação, tolerância e eficácia da DC baseada em fórmula em 10 crianças com epilepsia refratária. A DC apresentou adequada aderência e efeitos adversos leves. Além disso, 60\% dos pacientes apresentaram mais de $50 \%$ de redução frequência das crises e 10\% ficaram livres de crises.

Palavras-chave: dieta cetogênica; epilepsia; dietoterapia

Epilepsy is a devastating neurological disorder affecting approximately 50 million people of the world's population ${ }^{1}$. Pharmacotherapy with anti-epileptic drugs is the main strategy adopted for treatment, but $20-40 \%$ of patients continue to struggle with recurrent seizures despite medications ${ }^{2}$. Because of the physical, social, and psychological impact of even a single seizure, nonpharmacologic treatments such as dietary therapy have been considered to improve the quality of life of patients with medically-refractory epilepsy3.

Fasting has been used as a treatment for epilepsy since ancient times. The ketogenic diet $(\mathrm{KD})$ is a high-fat, low-carbohydrate, and restricted protein diet created in 1921 at the Mayo Clinic by Dr. R.M. Wilder to mimic the fasting state, which has been found useful in patients with refractory epilepsy ${ }^{4}$. The mechanism by which the $\mathrm{KD}$ leads to a reduction in seizures in these patients is not yet clear. In response to this diet and in the absence of glucose, ketone bodies produced from fatty-acid metabolism are used as the main energy source in the brain, maintaining a ketosis status ${ }^{5}$. Further evidence includes carbohydrate reduction, activation of adenosine triphosphate (ATP)-sensitive potassium channels by mitochondrial metabolism, inhibition of the mammalian target of rapamycin pathway, and inhibition of glutamatergic excitatory synaptic transmission ${ }^{5,6}$.

Patients with epilepsy syndromes and conditions such as myoclonic-atonic epilepsy (Doose syndrome), severe myoclonic epilepsy of infancy (Dravet syndrome), Rett syndrome, infantile spasm, and tuberous sclerosis complex may particularly benefit from the $\mathrm{KD}$. In addition, the $\mathrm{KD}$ is the treatment of choice for glucose transporter protein I deficiency and pyruvate dehydrogenase deficiency ${ }^{3}$.

The KD has been used worldwide ${ }^{7}$ and there are many alternative ketogenic diets such as the classical $\mathrm{KD}$, medium chain triglyceride diet, modified Atkins diet, and low glycemic index treatment ${ }^{8}$. The classical $\mathrm{KD}$ is calculated based on the ketogenic ratio, which refers to the ratio of the amount of fat to the combined amounts of protein and carbohydrate and is typically a 3:1 or 4:1 ratio. The amount of carbohydrates is minimal and every meal is calculated based on the energy and protein requirements of the patient ${ }^{9}$.

\footnotetext{
${ }^{1}$ Universidade de São Paulo, Faculdade de Medicina, Hospital das Clínicas, Instituto da Criança, Departamento de Neuropediatria, São Paulo SP, Brasil; ${ }^{2}$ Universidade de São Paulo, Faculdade de Medicina, Hospital das Clínicas, Instituto da Criança, Departamento de Nutrição, São Paulo SP, Brasil. Correspondence: Letícia Pereira de Brito Sampaio;Av. Dr. Enéas de Carvalgo Aguiar, 647; 05403-000 São Paulo SP, Brasil; E-mail: leticia.sampaio@hc.fm.usp.br Conflict of interest: There is no conflict of interest to declare.
}

Received 07 September 2016; Received in final form 14 December 2016; Accepted 06 January 2017. 
In Brazil, the $\mathrm{KD}$ is administered with solid foods and the most used ingredients are mayonnaise, bacon, eggs, heavy cream, meat, and some vegetables and fruits ${ }^{10}$. Since the $\mathrm{KD}$ is a highly restricted diet, one of the biggest challenges is to maintain patient adherence to the diet for at least two years. A formula-based KD can facilitate and improve the introduction of and adherence to the $\mathrm{KD}$ treatment for long periods in oral-fed children and can be especially practical and safe in tube-fed patients. The objective of this study was to evaluate the acceptability, tolerance, and efficacy of a formula-based $\mathrm{KD}$ in children with refractory epilepsy.

\section{METHODS}

Ten children with refractory epilepsy, who did not have remission of their seizures despite appropriate trials of two tolerated and appropriately chosen antiepileptic drugs, and who were referred to the $\mathrm{KD}$ program between October 2014 and June 2015 were included in the study. Children with disorders that contraindicated the use of the $\mathrm{KD}$ were excluded $^{2}$. This study was approved by the Research Ethics Committee at the Child Institute of the Clinical Hospital, University of São Paulo, Brazil. An informed consent was obtained from each parent or caregiver.

The KD was introduced in the outpatient setting. Before an initial screening visit, the patients' families were invited to a meeting to learn about the $\mathrm{KD}$ and the current trial. Next, they came for a visit, when the clinical history of the child was recorded and neurological and baseline exams were performed. Parents were instructed to record in a diary the frequency of seizures for one month from baseline and for the three months of treatment.

At the time of study entry, one child was taking one antiepileptic medication, one was taking two anti-epileptic medications, six children were taking three anti-epileptic medications, one child was taking four anti-epileptic medications, and one child was taking five anti-epileptic medications. The medications were not changed during the three-month study period.

For orally fed patients, we introduced the $\mathrm{KD}$ at a ratio of fat to protein and carbohydrate of 2:1 in the first week with solid foods distributed over four meals during the day. In the second week, we introduced a 3:1 KD powdered formula at two meals plus two meals with solid foods, and after another two weeks we introduced a 4:1 KD formula at two meals plus two meals with solid foods.

For enterally fed patients, we introduced a modulated 3:1 KD formula exclusively and, after two weeks, a 4:1 KD formula.

After starting the 4:1 diet, all children were reviewed as outpatients once a month, for three months.

We evaluated the acceptability, tolerance, and efficacy of the formula-based KD by the frequency of seizures, adverse events, level of ketosis, and intake of formula for the three-month period.

The frequency of seizures, adverse events, level of ketosis (whole blood $\beta \mathrm{HB}$ testing with a portable bedside machine or urine), and acceptability of the diet were recorded by the patient's parents. During the medical/dietitian visit, the records were checked and the parents were asked to rate the overall acceptability of the product and list any adverse events. Children received KetoCal 4:1 (Nutricia North America Inc., Gaithesburg, MD, USA).

\section{RESULTS}

Ten children (five boys) participated in the study. The age at the $\mathrm{KD}$ onset ranged from nine months to 16 years (mean: 6.3 years). All patients completed the three months of treatment (Table 1).

Ketone levels were measured in blood in six patients and a level of 3-5 mmol/L was achieved in 7-10 days. In four patients, ketone urine levels were measured and rated $++/+++$ on the $7^{\text {th }}$ and $15^{\text {th }}$ days in two children each. Two children did not have their ketosis level measured in the first three weeks. After three months, the responder rate (more than $50 \%$ seizure frequency reduction) was $6 / 10$ (60\%) and $10 \%(1 / 10)$ of patients were seizure-free.

The most frequently reported adverse effects were hunger, constipation, drowsiness, and hypoactivity, and one patient who received the formula exclusively presented with an intense perineal rash following the contact between the patient's feces and skin. Eight children reported improved attention and activity.

The formula was well accepted and tolerated by most patients and only one patient did not like its taste. Parents and clinicians considered that the formula was easy to use and facilitated the introduction of and adherence to the KD treatment. These results are shown in Table 2.

\section{DISCUSSION}

Due to the KD strictness, patient compliance depends on the type of diet and the patient population ${ }^{3}$. In Brazil, the $\mathrm{KD}$ was administered orally, or tube fed to children, using solid foods, and the most-used ingredients include mayonnaise, bacon, eggs, heavy cream, meat, and some vegetables and fruits. Despite the small number of patients in this study, the use of a formula-based $\mathrm{KD}$ was well accepted, tolerated and facilitated the compliance to the treatment.

The goal of the $\mathrm{KD}$ treatment is to bring the brain into a state of ketosis to control seizures. The traditional method of initiating the KD involves a period of fasting of 12-48 hours, depending on the urine ketone levels ${ }^{9}$. A prospective randomized study showed that fasting is not necessary for achieving 
Table 1. Demographic and clinical features.

\begin{tabular}{|c|c|c|c|c|}
\hline Case & Gender & Age at epilepsy onset & Etiology & Epilepsy type/Syndrome \\
\hline 1 & M & $1.5 y$ & Unknown & Lennox Gastaut syndrome \\
\hline 2 & M & $9 m$ & Unknown & Generalized and partial \\
\hline 3 & $\mathrm{~F}$ & $4 m$ & Unknown & Generalized \\
\hline 4 & F & $3 y$ & Encephalitis & Lennox Gastaut syndrome \\
\hline 5 & M & $7 m$ & Unknown & Lennox Gastaut syndrome \\
\hline 6 & $\mathrm{~F}$ & $1 y$ & Unknown & Generalized \\
\hline 7 & M & $4 m$ & Asphyxia & West syndrome \\
\hline 8 & $\mathrm{~F}$ & $3 m$ & Lyssencephaly & Lennox Gastaut syndrome/Lissencephaly \\
\hline 9 & M & $2 y$ & Unknown & Lennox Gastaut syndrome \\
\hline 10 & M & $4 m$ & Asphyxia & Partial \\
\hline
\end{tabular}

M:male; F: female; y:year; m: month

Table 2. Results.

\begin{tabular}{|c|c|c|c|c|c|c|c|}
\hline Case & $\begin{array}{l}\text { Age of } K D \\
\text { onset }\end{array}$ & Administration & Ketosis & $\begin{array}{l}\text { Days to reach } \\
\text { ketosis }\end{array}$ & Response & Acceptability & Adverse effects \\
\hline 1 & $6 y$ & Oral feeding & $4-5$ & 10 & Decreased $<50 \%$ & Good & $\begin{array}{c}\text { Hungry, obstipation and } \\
\text { hypoactivity }\end{array}$ \\
\hline 2 & $9 y$ & Tube feeding & $3-5$ & 8 & Decreased $>75 \%$ & Good & Perineal rash \\
\hline 3 & 3y & Oral feeding & $3-5$ & 7 & Decreased $<50 \%$ & Good & $\begin{array}{l}\text { Hungry, somnolence, obstipation, } \\
\text { lack of energy and improved QoL }\end{array}$ \\
\hline 4 & $16 y$ & Oral feeding & $2-3$ & 7 & Decreased $<50 \%$ & Good & $\begin{array}{c}\text { Drowsiness, hypoactivity and } \\
\text { improved QoL }\end{array}$ \\
\hline 5 & $3 y$ & Tube feeding & $4-5$ & 10 & Decreased $<50 \%$ & Good & Constipation and improved QoL \\
\hline 6 & $2 y$ & Oral feeding & $4-5$ & 8 & Decreased 100\% & Good & Improved QoL \\
\hline 7 & $9 m$ & Tube feeding & +++ & NA & Decreased $>75 \%$ & Good & $\begin{array}{l}\text { Hypoactivity, obstipation and } \\
\text { improved QoL }\end{array}$ \\
\hline 8 & $6 y$ & Oral feeding & +++ & NA & Decreased $>75 \%$ & Good & Improved QoL \\
\hline 9 & $5 y$ & Oral feeding & $++/+++$ & 7 & Decreased > 50\% & Good & $\begin{array}{l}\text { Hungry and obstipation and } \\
\text { improved QoL }\end{array}$ \\
\hline 10 & $4 y$ & Oral feeding & $++/+++$ & 15 & Decreased $>50 \%$ & Didn't like & Hungry and improved QoL \\
\hline
\end{tabular}

KD: ketogenic diet; y: year; m: month QoL: quality of life.

ketosis. In that study, the fasting KD group became ketotic earlier, but after six days, no difference was found in the degree of ketosis between the two treatment groups, and gradual initiation protocols offered the same results at three months, with lower frequency and severity of early side effects ${ }^{11}$. Fasting has the same effect as a "loading dose" of medication; however, acute adverse effects requiring patient hospitalization are more frequent ${ }^{11}$. Gradual $\mathrm{KD}$ onset allows the diet to be followed with less adverse effects on an outpatient basis, which is especially welcome where the availability of hospital beds is restricted. In the current study, satisfactory ketone levels were achieved, on average, 10 days after gradual $\mathrm{KD}$ onset for patients who were receiving a 3:1 KD formula.
A major limitation of the current study is the small cohort of patients, due to the limited quantity of the formula available for testing.

Besides that, not all patients measured ketosis in the same way and two children did not have their ketosis level measured in the first three weeks. Ketosis measured in the blood or urine is a reliable parameter. The two patients who did not measure ketosis had more than $75 \%$ of their seizures improved, which leads us to infer that they reached a good ketosis level, although we cannot determine the onset.

A randomized controlled trial that tested the efficacy of the $\mathrm{KD}$ in children with intractable epilepsy found that $62 \%$ of patients in the $\mathrm{KD}$ group had less than $50 \%$ reduction in 
seizures, $38 \%$ had more than $50 \%$ reduction in seizures, and $7 \%$ had more than $90 \%$ reduction in seizures at three months ${ }^{12}$. In our sample, $60 \%$ of patients had more than $50 \%$ seizure frequency reduction and $10 \%$ were seizure-free, which is a high response rate despite the small number of patients studied. Our sample population included five patients (50\%) with Lennox-Gastaut syndrome, who are more likely to experience a reduction in seizure frequency when receiving $\mathrm{KD}$ treatment ${ }^{13}$.

The KD powdered formula tested herein is nutritionally complete and has been successfully used in KDs, in Europe and in the United States of America, in patients with drugresistant epilepsy, but in Brazil has only recently become available. Although we describe a small cohort of patients, this study was important to evaluate the acceptance of the formula in our population, facilitating the introduction of an already well-established, but not yet prescribed, treatment that is often misinterpreted by medical professionals, dieticians and the general population as laborious and difficult to adhere to.

We observed only mild KD-related adverse events and they were not responsible for diet discontinuation. Gradual $\mathrm{KD}$ initiation protocols are, in general, associated with fewer and milder adverse events ${ }^{14,15}$. One patient had an intense perineal rash by contact that resolved with immediate hygiene after evacuation. This is the first report of this KD-related adverse event.

A well-balanced diet usually contains vitamins and minerals, but supplementation is essential for children receiving the KD due to the limited quantities of fruits and vegetables they can eat, making the use of a standard multivitamin necessary. Nevertheless, ketogenic formulas are enriched with vitamins and minerals and supplementation may not be necessary, depending on the amount of formula prescribed per day. Formula-based KD can be used in enterally fed patients to facilitate $\mathrm{KD}$ management and reduces administration mistakes in preparation when administered orally. Indeed, using a formula-based $\mathrm{KD}$ is simpler for dieticians to calculate, requires less family teaching, ketosis is easily maintained, and preparation errors are less common $^{3}$. However, children with epilepsy usually have several daily appointments, such as medical and nutritional consultations, tests, and therapies. Thus, homemade foods may not always be a practical solution since they are highly perishable and ketogenic formulas serve as a better dietary option for these patients. Moreover, introducing a successful $\mathrm{KD}$ in the outpatient setting can also reduce medical costs, as well as improving the quality of life of children with medically-refractory epilepsy as the number of seizures subsides. A barrier to the use of the formula in Brazil is the cost, making its use sporadic or limited to special situations.

In conclusion, epilepsy can have a high impact on the quality of life in children with intractable seizures and additional disabilities.

The ketogenic diet was effective in reducing the frequency of seizures and improving cognition and the quality of life of patients.

Homemade foods are normally used in the KD, but ketogenic formulas can be recommended to improve treatment acceptance and adherence.

\section{References}

1. World Health Organization - WHO. Epilepsy. Geneva: World Healh Organization; 2016 [cited 2016 Jul 23]. Disponivel em: http://www.who.int/mediacentre/factsheets/fs999/en/

2. Kwan P, Brodie MJ. Early identification of refractory epilepsy. N Engl J Med. 2000;342(5):314-9. https://doi.org/10.1056/NEJM200002033420503

3. Kossoff EH, Zupec-Kania BA, Amark PE, Ballaban-Gil KR, Christina Bergqvist AG, Blackford R et al. Optimal clinical management of children receiving the ketogenic diet: recommendations of the International Ketogenic Diet Study Group.Epilepsia. 2009;50(2):304-17. https://doi.org/10.1111/j.1528-1167.2008.01765.x PMID:18823325

4. Kossoff EH, Zupec-Kania BA, Rho JM. Ketogenic diets: an update for child neurologists. J Child Neurol. 2009;24(8):979-88. https://doi.org/10.1177/0883073809337162

5. Rho JM. How does the ketogenic diet induce anti-seizure effects? Neuroscience Letters. 2017;637:4-10. https://doi.org/10.1016/j.neulet.2015.07.034

6. Danial NN, Hartman AL, Stafstrom CE, Thio LL. How does the ketogenic diet work? Four potential mechanisms. J Child Neurol. 2013;28(8):1027-33. https://doi.org/10.1177/0883073813487598

7. Kossoff EH, Caraballo RH, du Toit T, Kim HD, MacKay MT, Nathan JK et al. Dietary therapies: a worldwide phenomenon. Epilepsy Res. 2012;100(3):205-9. https://doi.org/10.1016/j.eplepsyres.2011.05.024

8. Kossoff EH, Wang HS. Dietary therapies for epilepsy. Biomed J. 2013;36(1):2-8. https://doi.org/10.4103/2319-4170.107152
9. Freeman JM, Vining EP, Pillas DJ, Pyzik PL, Casey JC, Kelly LM The efficacy of the ketogenic diet-1988: a prospective evaluation of intervention in 150 children. Pediatrics. 1998;102(6):1358-63. https://doi.org/10.1542/peds.102.6.1358

10. Murakami D, Azevedo P. Dieta cetogênica. In: Silva APA, Nascimento AG, Zamberlan P, organizers. Manual de dietas e condutas nutricionais. São Paulo: Atheneu; 2014. p. 307-13.

11. Bergqvist AG, Schall JI, Gallagher PR, Cnaan A, Stallings VA. Fasting versus gradual initiation of the ketogenic diet: a prospective, randomized clinical trial of efficacy. Epilepsia. 2005;46(11):1810-9. https://doi.org/10.1111/j.1528-1167.2005.00282.x

12. Neal EG, Chaffe H, Schwartz RH, Lawson MS, Edwards N, Fitzsimmons $\mathrm{G}$ et al. The ketogenic diet for the treatment of childhood epilepsy: a randomised controlled trial. Lancet Neurol. 2008;7(6):500-6. https://doi.org/10.1016/S1474-4422(08)70092-9

13. Caraballo RH, Fortini S, Fresler S, Armeno M, Ariela A, Cresta A et al. Ketogenic diet in patients with Lennox-Gastaut syndrome. Seizure. 2014;23(9):751-5. https://doi.org/10.1016/j.seizure.2014.06.005

14. Wirrell EC, Darwish HZ, Williams-Dyjur C, Blackman M, Lange V. Is a fast necessary when initiating the ketogenic diet? J Child Neurol. 2002;17(3):179-82. https://doi.org/10.1177/088307380201700305

15. Kim DW, Kang HC, Park JC, Kim HD. Benefits of the nonfasting ketogenic diet compared with the initial fasting ketogenic diet. Pediatrics. 2004;114(6):1627-30. https://doi.org/10.1542/peds.2004-1001 